\title{
Experimental Tests of the Endowment Effect $^{1}$
}

\author{
Robert Franciosi, Praveen Kujal, Roland Michelitsch, \\ Vernon L. Smith, and Gang Deng
}

Individual decision-making studies have shown that human subjects reveal an asymmetric response pattern toward losses (loss aversion) as contrasted with gains measured relative to any individual's initial status quo position (Kahneman and Tversky. 1979). Consequently, if one's initial wealth endowment is $X_{0}$, then the hypothesis is that the utility function, $u(\cdot)$, has the property that $u\left(X_{0}-\mathrm{D} X\right)>u\left(X_{0}+\mathrm{D} X\right)$ for all deviations $\mathrm{D} X$ from any initial $X_{0}$. Although Kahneman and Tversky (1979) were concerned with prospect theory as a modification of utility theory for risky decisions, in a fundamental extension Thaler argued that "any of the elements of prospect theory can be used in developing descriptive choice models in deterministic settings" (Thaler, 1980, p. 41). Thaler observed that the utility property, $u\left(X_{0}-\mathrm{D} X\right)>u\left(X_{0}+\mathrm{D} X\right)$ implies that out-of-pocket costs are more heavily weighted in utility assessments than opportunity costs (i.e., a forgone gain has lower utility value than the actual loss of the same amount). This cognitive underweighting of opportunity costs by the individual was referred to as the endowment effect and was used to explain a number of questionnaire survey examples.

Subsequently, Kahneman et al. (1991; hereafter KKT) suggested that the discrepancy between willingness-to-pay (WTP) and willingness-toaccept (WTA), widely observed in hypothetical surveys and in motivated exchange experiments. were all manifestations of the endowment effect. (See KKT, Table 1 for a summary.) However, they argue (KKT, p. 1327) that the endowment effect does not apply when goods are purchased for resale rather than use. Thus there is no endowment effect for the retail firm. only for the consumer purchasing the firm's goods. Similarly, they note that it does not apply to the exchange of tokens (or rights) to which private redemption values, or induced values, have been assigned by the experimenter (Smith, 1976a). Empirically, they show

We thank Jack Knetsch for providing us with copies of the collected data from the KKT Experiments 6 and 7. 
this to be approximately the case in experiments establishing an endowment effect for Cornell and other coffee mugs but not for induced value tokens.

The results of nine experiments are reported by KKT. Some of these were exchange experiments, others were choice experiments using the Becker et al. (1964; hereafter BDM) procedure. In Section I, we discuss their choice experiments, introduce our modifications in their procedures, and present the new results. We replicate their procedures in pure choice experiments by removing all references to "buying" and "selling." The purpose is to remove all differential strategic motivation that might be suggested by these terms. In Section II, we discuss their exchange experiments and present the results of 10 new exchange experiments using the uniform-price double-auction mechanism which, because of its real-time information feedback features, achieves high efficiency in a single-period exchange.

\section{Choice Tests of the Endowment Effect}

\section{A. The KKT Experiments}

In their typical choice experiment, half of a group of subjects are randomly designated sellers and the others buyers. University coffee mugs costing about $\$ 6$ in the local university bookstore, are then distributed to the sellers, and all buyers are given the opportunity to examine a mug. The forms shown below are then executed by all sellers (buyers) (see KKT, p. 178, for their instructions).

For example. on this form a seller might indicate a preference for keeping the mug for all prices at or below $\$ 5.00$, selling it at all prices above \$5.00. The subject's WTA would then be assessed at \$5.25.

After the forms were executed, an equally likely price was drawn from

\begin{tabular}{l}
\hline $\begin{array}{c}\text { I will sell } \\
\text { (buy) }\end{array}$ \\
\hline If the price is $\$ 0$ \\
If the price is $\$ 0.50$ \\
If the price is $\$ 9.50$
\end{tabular}


Table 2.1. Mean WTA and WTP for university emblem mugs

\begin{tabular}{lllllll}
\hline Experiment & $\begin{array}{c}\text { WTA } \\
\text { sellers }\end{array}$ & $\begin{array}{c}\text { WTP } \\
\text { buyers }\end{array}$ & $\begin{array}{c}\text { WTA } \\
\text { choosers }\end{array}$ & $\begin{array}{l}\text { WTA-S } \\
\text { WTP-B }\end{array}$ & $\begin{array}{l}\text { WTA-S/ } \\
\text { WTA-C }\end{array}$ & $\begin{array}{l}\text { Sample } \\
\text { size. } N\end{array}$ \\
\hline KKT 6" and 7 & $\$ 6.89$ & $\$ 1.91$ & $\$ 3.05$ & 3.61 & 1.60 & 194 \\
& WTA & WTP & WTA & WTA-1/ & WTA-1/ & \\
& Group 1 & Group 2 & Group 3 & WTP-2 & WTA-3 & \\
UofA & $\$ 5.36$ & $\$ 2.19$ & $\$ 3.88$ & 2.45 & 1.38 & 120 \\
\hline
\end{tabular}

"Mugs and subjects from Simon Fraser University.

"Mugs and subjects from University of British Columbia. Price tags were left on the mugs. Mugs and subjects from University of Arizona. All subjects make choices. In Group 1. each is endowed with a mug: in Group 2, each is endowed only with the money earned in a preexperiment: in Group 3. each is endowed with the right to choose either a mug or additional money.

the list between $\$ 0$ and $\$ 9.50$, and exchanges based on this price were conducted by the experimenter. ${ }^{2}$ The results of their experiment 5 were typical of those reported by KKT: The median selling price, $\$ 5.75$, is more than double the median buying price, which is consistent with an endowment effect. But, as recognized by KKT, this interpretation is clouded by the fact that the experiment did not control for the income effect in standard preference theory.

To address this objection KKT (pp. 179-80) use three groups instead of two: sellers, buyers, and choosers. The sellers/buyers make the same sales/purchase decisions as before, whereas the choosers are asked to choose at each prospective price between the mug or cash. Thus sellers are given a mug, and choosers are given the right to either a mug or cash as they choose; any income effect on sellers as distinct from buyers, should also apply to choosers.

KKT report median prices for the three groups for each of two experiments (KKT, experiments 6 and 7,pp. 179-80). Mean prices for their data are shown in the first row of Table 2.1: Choosers behave much more like buyers than sellers, although choosers value mugs $60 \%$ more highly than buyers.

In some experiments, the ordered individual WTPs and WTAs are crossed, and the exchange is direclly between buyers and sellers at a common clearing price. But in these cases. it is no longer true "that your decision can have no effect on the price ..." as stated in the KKT instructions (p. 178). 
$B$.

\section{Choice Experiments Controlling for Differential} Instruction Effects

Because these last two experiments were critical to the hypothesized endowment effect. we conducted four experiments each with 24 subjects ( 8 in each group), having been motivated by the three-group design. However, we made several instructional changes, which, we conjectured, might be of substance.

Psychologically, buying, selling and choosing are distinct emotive terms. The first two are laden with strategic connotations - buyers are motivated to buy low and sellers to sell high - whereas choosing appears to be not so laden. To control for effects due only to differences in the KKT wording of the tasks for each of the three groups of subjects, we neutralized our instructions so that each group was presented with a choice task - not buying, selling, and choice tasks. Our instructions, common for all subjects, and the choice sheet for each of the three groups, now referred to with antiseptic evenness as Group 1, Group 2, and Group 3, are shown in an appendix supplied on request. Each member of Group 1 is an owner of an Arizona Wildcat mug and has the task of choosing, for each amount of money (not a price), between retaining the mug or accepting the additional amount of money. Each member of Group 2 is designated as having the right to choose between accepting a mug or retaining an amount of money out of their earnings in a previous experiment in the same session. Finally, each person in Group 3 is designated as having the right to choose between accepting a mug or accepting an additional amount of money. Thus, all subjects are symmetrically described as choosers, but under different initial conditions.

All our experiments were run at the end of two simultaneous postedoffer market experiments ( 6 buyers, 6 sellers in each), reported in Franciosi et al. (1994). The positions of Groups 1,2, and 3 were assigned at random among the 24 subjects. All subjects were paid their earnings in cash at the end of the market experiments. Earnings ranged from $\$ 8.75$ to $\$ 44.50$, providing all Group 2 subjects with adequate funds to give up for a mug if they chose.

The mean monetary amounts (prices) for each of Groups 1,2, and 3 are shown in the second data row of Table 2.1. The mugs were priced at $\$ 9.95$ (price tags removed) in the campus bookstore.

From Table 2.1, our subjects reported a substantially lower Group 1 WTA, a somewhat higher WTP. and a higher Group 3 WTA than did the KKT subjects. Substituting a choice task for the buying and selling tasks appears to narrow substantially the WTA/WTP discrepancy. But from Table 2.2 row 1, the $t$ test shows that all pairwise comparisons of our 
Table 2.2. Group distribution differences and comparisons with KKT results for buyers, sellers, and choosers using $\mathrm{t}$ tests

\begin{tabular}{|c|c|c|c|}
\hline Hypotheses & $\mathrm{G} 1=\mathrm{G} 2$ & $G 2=G 3$ & $G 3=\mathrm{Gl}$ \\
\hline Group $1-3$ & $\begin{aligned} t & =7.33 \\
\alpha & =0.000 \\
\mathrm{Gl} & =\mathrm{S}\end{aligned}$ & $\begin{aligned} t & =-4.01 \\
\alpha & =0.000 \\
\mathrm{G} 2 & =\mathrm{B}\end{aligned}$ & $\begin{aligned} t & =-2.98 \\
\alpha & =0.004 \\
\mathrm{G} 3 & =\mathrm{C}\end{aligned}$ \\
\hline KKT S. B, and C Groups & $\begin{aligned} t & =-3.73 \\
\alpha & =0.00\end{aligned}$ & $\begin{aligned} l & =1.10 \\
\alpha & =0.27\end{aligned}$ & $\begin{aligned} t & =2.12 \\
\alpha & =0.04\end{aligned}$ \\
\hline
\end{tabular}

three groups come from different distributions. Row 2 compares the KKT results with ours and shows that the reduction in selling prices and the increase in buying prices are significant using the $t$ test. Because these comparisons did not control for differences due to subjects and experimenters, we cannot attribute them only to the treatment differences.

We also asked if being in the role of buyer or seller in the prior market experiments affected the value revealed for a mug. The effect was insignificant using the Epps-Singleton test ( $\alpha=0.37$ ). Finally, we asked if the amount paid to subjects in the prior market experiments affected their revealed values in the mug experiment. A regression of the latter on the former yielded no significant relationship $\left(R^{2}=0.007\right)$. This suggests that any "house money" income effect on mug valuation is nil (Thaler and Johnson, 1990).

\section{Exchange Tests of the Endowment Effect}

A. The KKT Exchange Experiments

In addition to their choice experiments, KKT report the results of several exchange experiments. The typical experiment proceeds as follows. Of $2 N$ subjects, $N$ are randomly designated buyers, and $N$, sellers. The latter are each endowed with a mug; the former use their own money. Buyers each submit a bid price to buy a mug, sellers each submit an offer price to sell their mug. Their "bids" or "offers" are solicited by asking each subject to choose between a price and a mug for a series of prices as in the choice procedure. The bids (WTPs) of the subjects are then ordered from highest to lowest, whereas the offers (WTAs) are similarly ordered from lowest to highest. The intersection of these reported supply-anddemand schedules determines the price and quantity exchanged. If there 
are no endowment or income effects, then due to the random allocation of subjects to the buy or sell category the supply schedule of those given the mugs should be the symmetric mirror image of the demand schedule for those not given the cups [i.e., Demand " $D\left(P^{*}\right)=S\left(P^{*}\right)$ " $N-D\left(P^{*}\right)$ and $D\left(P^{*}\right)=N / 2$ ]. Consequently, the prediction is that $N / 2$ mugs will trade. For example (KKT, pp. 170-3), with 44 subjects, and $N$ $=22$ buyers and 22 sellers. 11 mugs are predicted to trade. In fact, between one and four trade at prices between $\$ 4.25$ and $\$ 4.75$. Although there are several bid/offer trials, only one is chosen at random to be binding. Table 2.3 summarizes their results for induced value tokens. mugs, and pens for all trials in four experiments.

According to the endowment hypothesis, the predicted number of trades will be realized for induced value tokens because one is simply trading dollars for identical dollar claims. In fact, on average, there is undertrading (in Experiments 2, 3, and 4 but not 1). This is consistent with other studies showing a tendency to underreveal (token) demand and/or supply by subjects in uniform price, sealed bid institutions (Smith et al., 1982). But with consumer goods (mugs, pens) there is substantial undertrading - much less than half the predicted volume is observed to trade. If there are income effects, then the demand by subjects not endowed with mugs is less than the demand by the endowed subjects, $d(P)<D(P)$. Hence $d\left(P^{*}\right)=N-D\left(P^{*}\right)<N-d\left(P^{*}\right)$ and $d\left(P^{*}\right)<N / 2$. But our finding reported earlier, showing no income effect, suggests that this cannot account for the results in Table $2.3 .^{+}$

We should add that the KKT procedure does produce an incentive to underreveal demand (supply). When subjects are asked to choose between an object and a price, they know that their crossover price is, in effect, a bid price for a buyer and an ask price for a seller. Then "the market price was the point at which the elicited supply and demand curves intersected" (KKT, footnote 2, p. 171). This procedure means that if the highest accepted ask is less than the lowest accepted bid, $A_{11}<B_{1}$. then there are many prices that clear the market. The typical (fair?) procedure is to set the clearing price at $P_{C}=\left(A_{\mathrm{H}}+B_{\mathrm{L}}\right) / 2$. The mug price in trial 6 of experiment 1 is an example in which $P_{c}$ is half way between

Sometimes it has been suggested that subjects trade in induced value experiments because they think the experimenter expects it and brought them to the lab for this purpose. The KKT results are quite contrary to this interpretation.

+ One could also usc our WTP and WIA data from the choice experiments to determine a hypothetical exchange quantity based upon the BDM elicitation procedures. We performed this excreise by crossing the Group 1 WTA with the Group 2 WTP and found that of 20 predicted trades only 8 would occur. This undertrading is consistent with the findings of KKT. If we use the Group 3 data as a better estimate of "true WTA" and cross these with the Group 2 WTP. we still get only 12 of 20 predicted trade. 
Table 2.3. Predicted and observed trades for different objects

\begin{tabular}{|c|c|c|c|c|c|c|}
\hline Experiment & Total & $\begin{array}{l}\text { Number } \\
\text { subjects }\end{array}$ & Object & Price & $\begin{array}{c}\text { Observed } \\
\text { trades }\end{array}$ & $\begin{array}{l}\text { Predicted } \\
\text { trades }\end{array}$ \\
\hline 1 & 1 & 44 & Tokens & $\$ 3.75$ & 12 & 11 \\
\hline 1 & 2 & 44 & Tokens & $\$ 4.75$ & 11 & 11 \\
\hline 1 & 3 & 44 & Tokens & $\$ 4.25$ & 10 & 11 \\
\hline 1 & 4 & 44 & Mugs & $\$ 4.25$ & 4 & 11 \\
\hline 1 & 5 & 44 & Mugs & $\$ 4.75$ & 1 & 11 \\
\hline 1 & 6 & 44 & Mugs & $\$ 4.50$ & 2 & 11 \\
\hline 1 & 7 & 44 & Mugs & $\$ 4.25$ & 2 & 11 \\
\hline 1 & 8 & 44 & Pens & $\$ 1.25$ & 4 & 11 \\
\hline 1 & 9 & 44 & Pens & $\$ 1.25$ & 5 & 11 \\
\hline 1 & 10 & 44 & Pens & $\$ 1.25$ & 4 & 11 \\
\hline 1 & 11 & 44 & Pens & $\$ 1.25$ & 5 & 11 \\
\hline 2 & 1 & 38 & Tokens & $\$ 3.75$ & 10 & 10 \\
\hline 2 & 2 & 38 & Tokens & $\$ 4.75$ & 9 & 10 \\
\hline 2 & 3 & 38 & Tokens & $\$ 4.25$ & 7 & 8 \\
\hline 2 & 4 & 38 & Mugs & $\$ 1.75$ & 3 & 9.5 \\
\hline 2 & 5 & 38 & Mugs & $\$ 2.25$ & 3 & 9.5 \\
\hline 2 & 6 & 38 & Mugs & $\$ 2.25$ & 2 & 9.5 \\
\hline 2 & 7 & 38 & Mugs & $\$ 2.25$ & 2 & 9.5 \\
\hline 2 & 8 & 38 & Binoculars & $\$ 1.25$ & 4 & 9.5 \\
\hline 2 & 9 & 38 & Binoculars & $\$ 0.75$ & 4 & 9.5 \\
\hline 2 & 10 & 38 & Binoculars & $\$ 0.75$ & 3 & 9.5 \\
\hline 2 & 11 & 38 & Binoculars & $\$ 0.75$ & 3 & 9.5 \\
\hline 3 & 1 & 26 & Tokens" & - & 5 & 6.5 \\
\hline 3 & 2 & 26 & Pons' & - & 2 & 6.5 \\
\hline 3 & 3 & 26 & Pens ${ }^{\prime t}$ & - & 2 & 6.5 \\
\hline 3 & 4 & 26 & Pens" & - & 2 & 6.5 \\
\hline 3 & 5 & 26 & Pens' & - & 1 & 6.5 \\
\hline 4 & 1 & 74 & Tokens" & - & 15 & 18.5 \\
\hline 4 & 2 & 74 & Tokens" & - & 16 & 18.5 \\
\hline 4 & 3 & 74 & Mugs" & - & 6 & 18.5 \\
\hline 4 & 4 & 74 & Mugs" & - & 4 & 18.5 \\
\hline 4 & 5 & 72 & Mugs" & - & 4 & 18 \\
\hline 4 & 6 & 73 & Mugs" & - & 8 & 18 \\
\hline 4 & 7 & 74 & Mugs" & - & 8 & 18.5 \\
\hline
\end{tabular}

"Prices are not reported in experiments 3 and 4 in these experiments; "the subjects were asked for minimum selling or maximum buying prices rather than answer the series of yes or no questions used in Experiments 1 and 2" (KKT. p. 175). 
Table 2.4. Bid, offers and trades uniform-price double-auction experiment 7302, period 12

\begin{tabular}{rrrrr}
\hline ID No. & Bid & Rank & Offer & ID No. \\
\hline 2 & 400 & 1 & 220 & 19 \\
6 & 325 & 2 & 290 & 24 \\
9 & 310 & 3 & 300 & 22 \\
4 & 310 & 4 & 300 & 21 \\
11 & 301 & 5 & 300 & 17 \\
12 & 300 & 6 & 300 & 27 \\
10 & 311 & 7 & 329 & 25 \\
7 & 300 & 8 & 330 & 26 \\
1 & 300 & 9 & 347 & 18 \\
8 & 280 & 10 & 362 & 23 \\
5 & 270 & 11 & 380 & 20 \\
3 & 200 & 12 & - & - \\
\hline
\end{tabular}

the discrete values $\$ 4.25$ and $\$ 4.75$ on the subject's choice form. If subjects believe that $A_{\mathrm{H}}<B_{\mathrm{t}}$ is a possible outcome, it pays any seller (who may turn out to be the marginal seller) to ask more than her WTA (or marginal buyer to bid below his WTP). Because the distribution of the consumer good object values is highly uncertain and unknown to both the subjects and the experimenters, the incentive to underreveal may be more pronounced than with tokens.

\section{B. The Uniform-Price Double-Auction Mechanism}

There exists a trading institution that results in a single block trade called the Uniform-Price Double Auction but that has the real-time feedback characteristics of the continuous double auction. It has been extensively studied in the laboratory (McCabe et al., 1993; Friedman, 1991). Bids and offers are displayed in real time and continuously crossed to yield a provisional clearing price and quantity while the market is open. When the trading period ends, all trades become binding at the price and quantity standing at the close. This institution is particularly well suited for examining the exchange predictions of the endowment effect because it has been shown to have excellent revelation properties for marginal units, resulting in fully efficient exchange. Table 2.4 and Figure 2.1 illustrate the state of all bid and offer realizations at the market close for a lypical trading period in an experiment (period 12, experiment 7302). 

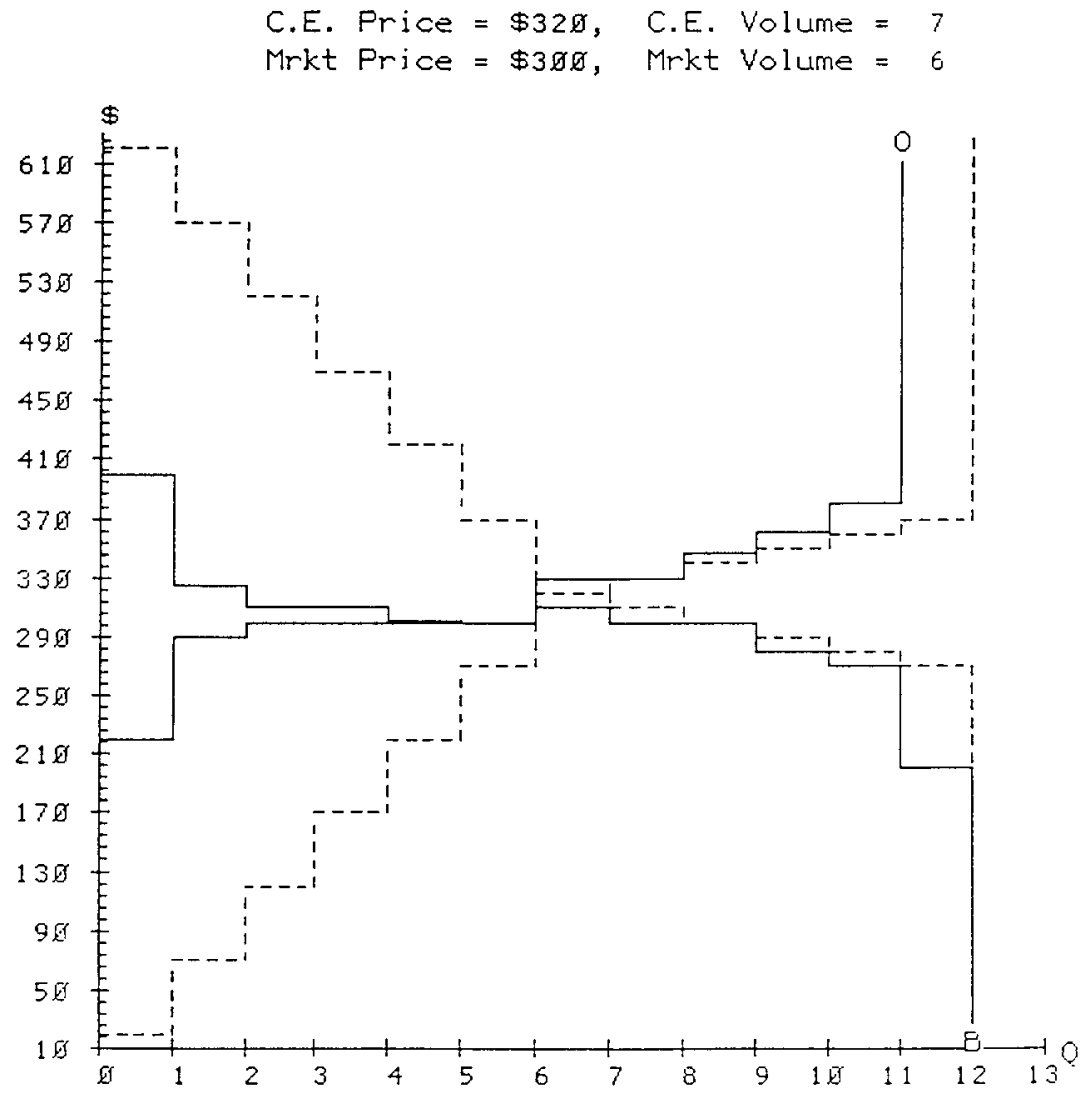

FIGURE 2.1. Graph of induced supply and demand and of bid/offer realizations. UPDA experiment 7302, period 12.

The first column lists the identification number of each buyer, followed by that buyer's bid (column 2). The rank order (high to low of bids, low to high of offers) is shown in column 3. Column 4 displays each seller's offer followed by the seller's identification number in column 5 . The horizontal line below the sixth ranked bid and offer separates the accepted bids and offers above from the rejected bids and offers below the line. The accepted bids and offers form contracts at a uniform price (300) cents in Table 2.4). Several alternative information feedback and price algorithm procedures for this mechanism have been studied. We use the procedure in which subjects see displayed in real time only the best rejected bid and offer ( 311 cents and 329 cents in Table 2.4 ). This places maximum 
Table 2.5. Description of treatments in exchange experiments

\begin{tabular}{|c|c|c|}
\hline & Series 1 & Series 2 \\
\hline Part 1 & $\begin{array}{l}\text { Induced values }[0 . \$ 9.99] \text { : } \\
\text { random equilibrium: 4-min periods }\end{array}$ & $\begin{array}{l}\text { Induced values }[0, \$ 9.99] \text { : } \\
\text { constant equilibrium: } 4 \text {-min periods }\end{array}$ \\
\hline Part 2 & $\begin{array}{l}\text { Buycrs: } \$ 9.99 \text { each: sellers: one } \\
\text { mug each: } 4 \text {-min periods }\end{array}$ & $\begin{array}{l}\text { Buyers: } \$ 9.99 \text { each: sellers: one } \\
\text { mug each: } 4 \text { - and } 6 \text {-min periods; } \\
\$ 9.95 \text { lag left on mug }\end{array}$ \\
\hline $\begin{array}{l}\text { Number of } \\
\text { experiments } \\
\text { (subjects) }\end{array}$ & $4(96)$ & $6(144)$ \\
\hline
\end{tabular}

pressure on the outside traders to reach agreement and has been found to yield the highest exchange volume and market efficiency (McCabe et al., 1993, p. 320).

In Figure 2.1 the demand bids (supply offers) are plotted as solid line steps. Also plotted as broken line steps are the induced value or cost of each trader. Note the substantial value/cost underrevelation, which does not thereby impede the efficient exchange of six units.

\section{Mug Exchange Using the Uniform-Price Mechanism}

We report the results of two series of experiments. In each experiment 24 different subjects were randomly assigned to groups of 12 buyers and 12 sellers. Each series was divided into Parts 1 and 2 (see Table 2.5). In Part 1 of Series 1, each buyer was assigned a value and each seller a cost by a random draw with replacement from the uniform distribution on $[\$ 0, \$ 9.99]$ at the beginning of each of 10 (or 12) trading periods. This baseline served as a training session. All periods lasted 4 minutes. In Part 2. Scries 1 and 2, each buyer was endowed with a $\$ 9.99$ cash balance, which was theirs to keep if no mug was purchased; each seller was endowed with a University of Arizona emblem mug priced at $\$ 9.95$ in the university bookstore and theirs to keep if not sold. Each subject was paid in cash all of his or her earnings from the induced value training experiments in Part 1 of each of the sessions. In Series 2, Part 1 used the constant volume equilibrium environment shown in Figure 2.1, but in each period a random constant was added to each value, and the values were randomly assigned to individuals. Part 2 of Series 2 was like that of Serics 1 except that the price tag $(\$ 9.95)$ was left on each mug. and this 
was pointed out to the subjects. This was a treatment to reduce uncertainty concerning the cash or market value of the mug in each group. Also in Series 2 we increased the trading time for the mug exchange from 4 to 6 minutes in four of the six experiments. This is because it appeared that the subjects were still adjusting their bids and offers when the period ended after 4 minutes. Table 2.5 summarizes the experimental design.

Table 2.6 lists the predicted competitive equilibrium volume and the corresponding observed trading volume in periods 1-10 for the random equilibrium-induced value environment. The induced value results are those recorded for periods $1-10$ in four experiments. The mug exchange volume is recorded in period 11 for each experiment, with the corresponding clearing price shown in parenthesies.

Table 2.7 lists the volume data for the experiments using a constant equilibrium volume environment for periods $1-12$ in the training baseline. Period 13 records the volume in the subsequent mug exchange experiments, with the clearing price shown in parentheses.

In both Tables 2.6 and 2.7, as we move from induced value exchange to mug exchange, volume relative to the prediction is decreased. However, when we compare the mug exchange volume in Tables 2.6 and 2.7 with the various objects exchanged in Table 2.3 , it is clear that our exchange mechanism results in much less undertrading than was observed by KKT. In 3 of our 11 experiments, half or more of the mugs traded as predicted by standard theory.

Because earnings in the induced value experiments vary from zero to $\$ 34$, we can ask if there are any income effects on the submitted bids or offers of subjects in the mug experiments. Separate regressions of such bids (offers) on earnings for buyers and for sellers yield no significant effect of earnings on subject WTP or WTA for a mug (the regression coefficients yield $t$ values of -0.28 for sellers and -0.20 for buyers). Again, there is no income, or house money effect.

Each mug exchange experiment provides a sample of bid and offer prices standing at the close of each experiment. Because the exchange mechanism provides full opportunity for each subject to adjust his or her bid or offer price to the level needed to produce a trade. if a trade is truly desired, the resulting distributions of bids and offers provide market incentive-based measures of WTA and WTP that are distinct from the BDM measures elicited in Groups 1 and 2 in Section 1. It is therefore of interest to compare the distribution of the Group 1 WTA prices with the distribution of closing exchange offers and the Group 2 WTP prices with 


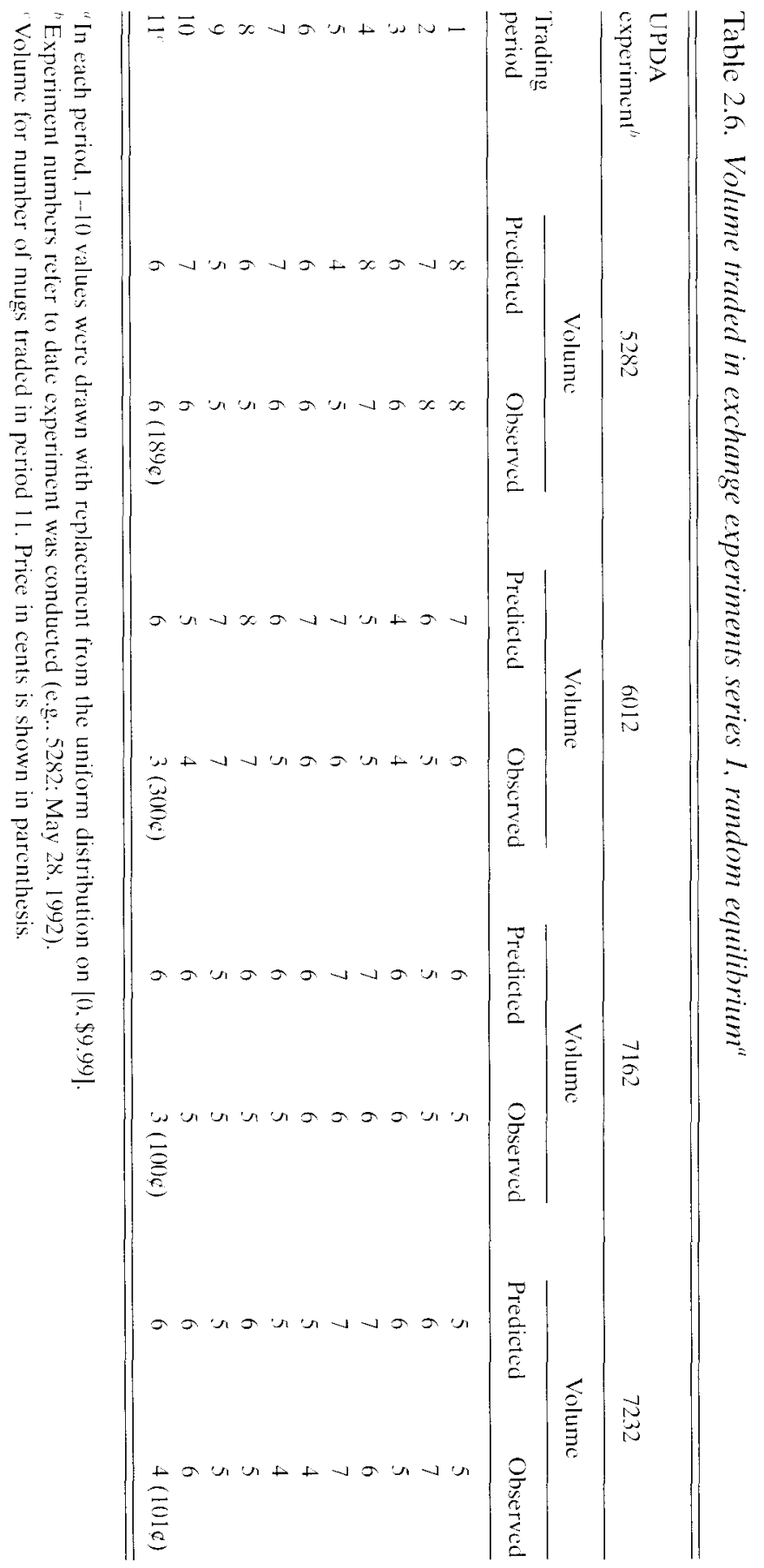




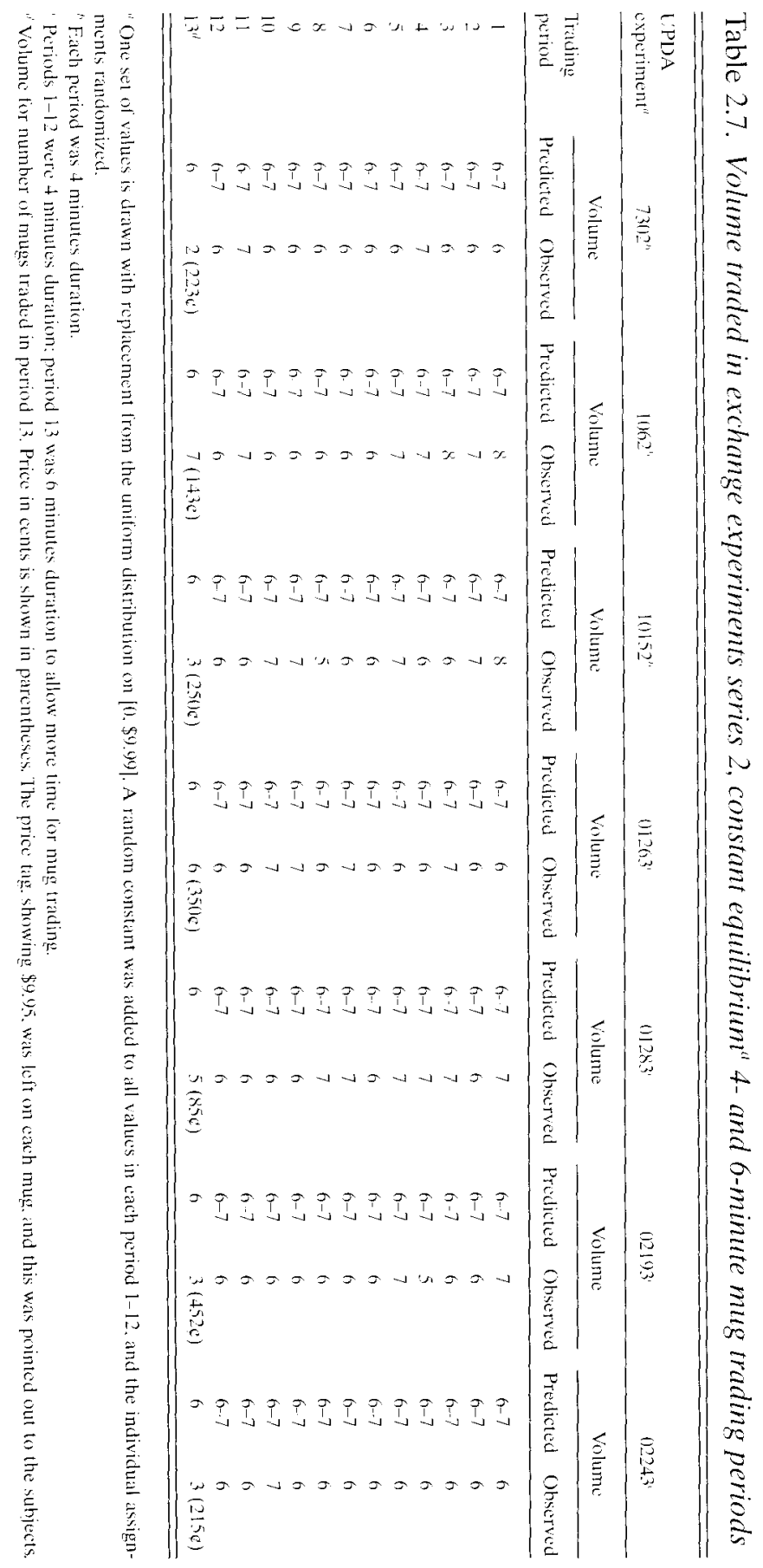


Table 2.8. Comparison of UPDA bids, offers, and exchange prices with choice valuations

\begin{tabular}{llccr}
\hline \hline & & Bids & Offers & \multicolumn{1}{c}{ Prices } \\
\hline Group 1 WTAs & $t$ statistic prob. level & - & $-8.68(0.00)$ & $-4.14(0.00)$ \\
Group 2 WTPs & $t$ statistic prob. level & $-9.043(0.00)$ & - & $0.14(0.89)$ \\
\hline \hline
\end{tabular}

closing exchange bids. We report these $t$ test comparisons in Table 2.8 . In these comparisons, we use only the bid-offer data for the exchange experiments in which the mug prices were unknown because this was the treatment condition in the choice data for Groups 1 and 2. Both the offer and the bid distributions are significantly below the corresponding Group 1 WTA and Group 2 WTP distributions. The choice procedure does not yield valuations that are good predictors of the actual bids and offers submitted in the iterative market setting.

Also in Table 2.8 we report comparisons of the Group 1 and 2 valuations with the sample of all mug prices from the exchange experiments. These comparisons show that prices are significantly below the Group 1 WTAs but not the Group 2 WTPs. Thus the WTPs based on choice data are a better indicator of the level of exchange prices than are the WTAs. Coursey et al. (1987) report similar findings in their study of the disparity between WTA and WTP.

In a new study using repeated second price auctions to measure WTP and WTA for goods with close substitutes (candy bars and mugs). Shogren et al. (1994) found no significant difference between the average of WTA and WTP (or price) for these goods. These carefully conducted new experiments cast doubt upon the WTA/WTP discrepancy for goods with close substitutes, and they rejected the KKT hypothesis of an endowment effect. Thus, for mugs Shogren et al. (1994. p. 265) reported WTA/WTP ratios of only 1.08 and 1.05 in two treatments on the final three trials $8-10$.

We have no disagreement with their results or conclusions. Their results are not inconsistent with our market results because we directly examine trading volume not the WTA/WTP discrepancy. It is very important to realize that mean differences between WTA and WTP in two situations can be indistinguishable statistically, yet trading volume can differ substantially. To see this look at Fig. 2.1. On average, a slight decrease (increase) in the last four accepted bids (offers) would have no discernible effect on the difference between WTA and WTP; however, 
that there does, indeed, appear to be undertrading due to an endowment effect. But, as noted later, our interpretation is different.

A comparison of the bid (offer) distribution in the mug exchange experiments with the WTP (WTA) distribution in the choice experiments shows that both the bid and the offer distributions in exchange are below those in the choice experiments: Buyers bid less and sellers offer less in actual exchange than is revealed by the choice procedure. A similar comparison with the exchange mug prices reveals that the WTP distribution in the choice experiment is a better indicator of market value than the WTA distribution.

We accept the Shogren et al. (1994) finding of no statistically significant difference between WTA and WTP (for mugs, candy bars) using second price auction measures. They show that the difference does indeed become trivial relative to sampling variability over time. But we observe undertrading relative to predictions, which is entirely consistent with persistent small statistical differences between WTA and WTP. Consequently, we are unable to reject the KKT undertrading hypothesis. Statistical insignificance in the WTA-WTP space is associated with economically significant reductions in trade. This can be explained by the fact that in our experiments and in KKT, the reported supply and demand schedules are very flat. Thus, very small discrepancies between WTA and WTP have large effects on undertrading.

As we interpret the evidence, the key hypothesis in KKT that withstands market scrutiny is not the disparity between WTA and WTP but undertrading. The latter, however, appears to be primarily an artifact of the gently sloped reported supply and demand.

Is the endowment effect an important characteristic of behavior that should concern us? As an observation contrary to standard preference theory, it cannot be lightly dismissed. As a matter of practical importance in markets, it is perhaps of little concern. Trade is almost entirely between specialist firms selling to other firms or consumers, not consumers selling to consumers. Garage sales are an exception to the latter where it appears that the propensity to truck barter and exchange is alive and well, even if there is undertrading. Finally, if Shogren et al. (1994) are right - the WTA/WTP discrepancy becomes trivial over time - then significant undertrading may be an artifact of flat supply and demand schedules. 